\title{
Associations among Postpartum Depression, Eating Disorders, and Perfectionism in a Population-Based Sample of Adult Women
}

\author{
Suzanne E. Mazzeo, $\mathrm{PhD}^{1,2 *}$ \\ Margarita C.T. Slof-Op't \\ Landt, $\operatorname{Ir}^{3}$ \\ Ian Jones, $\mathrm{MD}^{4}$ \\ Karen Mitchell, BS ${ }^{1}$ \\ Kenneth S. Kendler, MD 5,6 \\ Michael C. Neale, PhD $^{5,6,7}$ \\ Steven H. Aggen, PhD, ${ }^{5,6}$ \\ Cynthia M. Bulik, PhD ${ }^{8,9}$
}

\begin{abstract}
Objective: The current study investigated associations among eating disorders, depressive symptoms during pregnancy and postpartum, and perfectionism in a population-based sample of women
\end{abstract}

Method: Females who reported $\geq 1$ pregnancy $(N=1,119)$ completed questionnaires assessing perfectionism, eating disorder symptomatology, and depression during pregnancy and postpartum. Information regarding participants' history of major depressive disorder (MDD) was also available from structured psychiatric interviews completed during a previous wave of data collection.

Results: Depressive symptoms during pregnancy and postpartum were high among women with a history of eating disorders. Both binge eating disorder (BED) and bulimia nervosa (BN) were positively associated with symptoms of postpartum depression (PPD), even when lifetime MDD was controlled. However, Io- gistic regression indicated that women with a history of BN and BED are at particular risk of developing PPD symptomatology. Linear regression analyses conducted with the subset of the sample who endorsed a PPD screening item suggested that the severity of PPD symptomatology may be attributable to Concern Over Mistakes, a specific aspect of perfectionism.

Conclusion: These results highlight the importance of assessing specific features of perfectionism. In addition, they suggest that women with $\mathrm{BN}$, BED, or high Concern over Mistakes may be at particular risk of developing PPD symptoms, and could benefit from prenatal screening. (C) 2006 by Wiley Periodicals, Inc.

Keywords: postpartum depression; eating disorder behaviors; eating attitudes; pregnancy

(Int J Eat Disord 2006; 39:202-211)
Accepted 31 August 2005

Supported by Grants MH-068520-02 (SEM) and MH-01553 (CMB) from the National Institutes of Health

${ }^{*}$ Correspondence to: Suzanne E. Mazzeo, PhD, Department of Psychology, Virginia Commonwealth University, P.O. Box 842018 , Richmond, VA 23284-2018. E-mail: semazzeo@vcu.edu

1 Department of Psychology, Virginia Commonwealth University, Richmond, Virginia

${ }^{2}$ Department of Pediatrics, Virginia Commonwealth University, Richmond, Virginia

${ }^{3}$ National Centre for Eating Disorders, Leidschendam/ Oegstgeest, The Netherlands

${ }^{4}$ Department of Psychological Medicine, Cardiff University, Wales, United Kingdom

${ }^{5}$ Virginia Institute for Psychiatric and Behavioral Genetics, Virginia Commonwealth University, Richmond, Virginia

${ }^{6}$ Department of Psychiatry, Virginia Commonwealth University, Richmond, Virginia

${ }^{7}$ Department of Human Genetics, Virginia Commonwealth University, Richmond, Virginia

${ }^{8}$ Department of Psychiatry, University of North Carolina, Chapel Hill, North Carolina

${ }^{9}$ Department of Nutrition, University of North Carolina, Chapel Hill, North Carolina

Published online 23 February 2006 in Wiley InterScience (www.interscience.wiley.com). DOI: 10.1002/eat.20243

(C) 2006 Wiley Periodicals, Inc.

\section{INTRODUCTION}

Relatively little is known about pregnancy and parenting among women with current or past eating disorders. Yet, clinical data suggest that many women with eating disorders are becoming mothers. ${ }^{1-4}$ Consequently, pregnancy and motherhood have become the focus of increased attention among eating disorder researchers. ${ }^{1,2,4-8}$ These studies have indicated that, for many women with eating disorders, pregnancy leads to temporary symptom remission., $, 5,7,9,10$ However, relapse is common postpartum. ${ }^{4,7,9,11}$

One issue that might be particularly relevant to eating disorder relapse is depression during pregnancy and postpartum. High rates of comorbidity between eating disorders and major depressive disorder (MDD) have been identified in numerous studies. ${ }^{12-19}$ However, much less is known about depression during pregnancy and the postpartum period among women with eating disorders. In addition, some women have reported that their eat- 
ing disorders began in the postpartum period, as they attempted to lose weight gained during pregnancy. ${ }^{20-22}$

Therefore, the main focus of the current study was to evaluate associations among eating disorder diagnoses (anorexia nervosa [AN], bulimia nervosa $[\mathrm{BN}]$, and binge eating disorder [BED]) and depression during pregnancy and postpartum. In addition, the influence of perfectionism on the association between postpartum depression (PPD) and eating disorders was evaluated, as perfectionism has recently been found to be a trait with considerable relevance to eating pathology. ${ }^{23-25}$ The following sections briefly review the prevalence and significance of depression during pregnancy and postpartum and discuss what is known about these issues in women with eating disorders. Finally, we review the potential relevance of perfectionism to the association between PPD and eating disorders.

\section{Depression during Pregnancy and Postpartum}

Epidemiologic research indicates that approximately $10 \%-17 \%$ of women in the general population experience depression during pregnancy. ${ }^{26,27}$ In addition, many mothers experience a phenomenon known as the "postpartum blues" within a few days of childbirth. ${ }^{28}$ These mild mood symptoms occur in as many as $80 \%$ of women, and generally subside within approximately 2 weeks postpartum..$^{28}$ However, approximately $25 \%$ of women who report postpartum blues later develop more severe PPD. ${ }^{29}$ In 1 of the most comprehensive, population-based studies conducted to date, Josefsson et $\mathrm{al}^{26}$ found that $18 \%$ of Swedish women reported symptoms of depression 6-8 weeks postpartum, and $13 \%$ continued to be depressed 6 months postpartum. These rates have led some to call PPD "the most common complication of childbirth" (MosesKolko and Roth, p 182). ${ }^{28}$

PPD not only negatively impacts mothers' functioning, but also is associated with social, emotional, cognitive, and behavioral difficulties in offspring. ${ }^{28,30,31}$ Given that children of mothers with eating disorders already appear to be at a higher than average risk for psychological problems, ${ }^{32}$ it is important to identify whether women with eating disorders might be at particular risk for developing depressive symptoms postpartum, so that this problem could be detected and treated expeditiously.

\section{PPD in Women with Eating Disorders}

One of the few studies to examine the association of PPD with AN and BN was conducted by Franko et al. ${ }^{2}$ These authors investigated the pregnancies of 49 women who had previously sought eating disorder treatment and found that $34.7 \%$ experienced PPD. It is noteworthy that no differences were found in PPD rates of women who manifested eating disorder symptomatology during their pregnancies and those who did not. However, all of the women who developed PPD had a lifetime history of a mood disorder.

Morgan et al. ${ }^{4}$ investigated PPD among a treatment-seeking sample of 94 women who had active $\mathrm{BN}$ at conception. They found that approximately one third developed PPD within 4 weeks of childbirth. Moreover, women with $\mathrm{BN}$ at conception, as well as a history of $\mathrm{AN}$, appeared to be at even greater risk for PPD; two thirds of this subgroup developed PPD. Furthermore, although pregnancy was associated with $\mathrm{BN}$ remission for many women, PPD was associated with eating disorder relapse postpartum; $94 \%$ of individuals with PPD experienced a relapse of BN. In contrast, $52 \%$ of women without PPD experienced a relapse of BN postpartum. PPD was also associated with alcohol abuse (at conception), higher postpartum binge frequency, and a lower body mass index (BMI; at conception).

Comparable rates of PPD were found in Abraham's ${ }^{33}$ study of 25 women with BN who had given birth 10-15 years after initially seeking treatment for BN. Specifically, $36 \%$ of this sample reported experiencing clinically significant PPD. However, a recent longitudinal study conducted by Carter et al. ${ }^{6}$ compared women who did and did not give birth within 5 years of seeking treatment for BN. They found that childbirth was not associated with an increased risk of depression in either the year of childbirth or in the subsequent year. In contrast, the women who did give birth during the follow-up period manifested less eating disorder and depressive symptomatology than the women who did not. Carter et al. ${ }^{6}$ note that their study only included participants who had completed treatment before giving birth, which might explain why their results differed from those of other studies that have generally assessed PPD in women with active eating disorders. These results complement those of a previous study conducted by this group, ${ }^{1}$ which found that women with more severe BN symptoms at 5-year treatment follow-up were less likely to conceive than those with less BN symptoms. Taken together, these results highlight the need to evaluate the association between PPD and eating disorder history in non-treatment-seeking samples.

Another study conducted by Abraham et al. ${ }^{34}$ investigated depression in 181 women who had 
given birth the week before the study. They found that women who were most concerned about their weight before and during pregnancy were the most likely to report depressive symptomatology 1 week postpartum. However, a limitation of this study is that, because the women had given birth so recently, it was impossible to determine how many were suffering from the relatively normative "baby blues," as opposed to the more clinically significant PPD. In contrast, the current study assesses both baby blues and PPD.

\section{Perfectionism and PPD among Women with Eating Disorders}

Perfectionism is another common characteristic of individuals with eating disorders. ${ }^{23-25}$ Indeed, perfectionist features are often evident before the development of both $\mathrm{AN}^{35,36}$ and $\mathrm{BN}^{37}$ Further, individuals who have recovered from eating disorders (both $\mathrm{AN}$ and $\mathrm{BN}$ ) are more likely to manifest perfectionism than controls. ${ }^{38-41}$ Moreover, perfectionism and related personality traits are relatively common in family members of individuals with eating disorders. ${ }^{24,42,43}$

Recent research has also identified an association between eating disorder symptoms and specific components of perfectionism, namely, tendencies to interpret mistakes as failures (i.e., Concern over Mistakes [CM]) and to doubt one's ability to accomplish tasks (i.e., Doubts about Actions [DA].$^{25}$ In addition, three studies have found evidence for the familial transmission of CM. First, Woodside et al. $^{43}$ reported that, compared with controls, CM was higher among mothers of individuals with AN. A second study ${ }^{24}$ found that firstdegree female relatives (with no history of eating disorders) of individuals with AN had higher scores on CM compared with relatives of controls. Third, a recent twin investigation of perfectionism ${ }^{44}$ found that the overall construct was moderately heritable. Multivariate structural analyses suggested that CM was the core feature of the latent construct of perfectionism. DA and Personal Standards (PS) were also identified but were less central in defining the perfectionism construct. Overall, these genetic studies highlight the relevance of perfectionism as an important construct increasing vulnerability to eating-disordered behavior. Further, they emphasize the importance of using a multidimensional measure of perfectionism.

Finally, previous research has found that perfectionism is associated with depression in the presence of life stress or daily hassles. ${ }^{45}$ Parenting an infant and recovering from childbirth represent considerable life stressors. However, research has not examined whether perfectionism is associated with PPD symptoms among women with eating disorders. Given the frequency of perfectionist features in women with eating disorders, it is possible that perfectionist tendencies may extend to the realm of mothering. Women with eating disorders may have unrealistic expectations of themselves as mothers, which could increase their vulnerability to PPD when these high self-imposed expectations are not met. Thus, in the current study, we investigated associations among eating disorder diagnoses, components of perfectionism, and PPD symptoms.

\section{Purpose of the Study}

A limitation of previous studies examining eating disorders and depression during pregnancy and postpartum is that relatively small and exclusively clinical samples have been used, which may produce biases with respect to the severity of eating disorders and comorbid symptoms. ${ }^{46}$ Women who seek treatment for eating disorders are more likely to have comorbid conditions, including affective disorders, ${ }^{47}$ and may not be truly representative of the population of individuals with eating disorders. Consequently, the first aim of the current study was to examine depression during pregnancy and postpartum in a large, population-based sample of women, controlling for a previous lifetime history of MDD.

A second aim was to evaluate the prevalence of depression during pregnancy and postpartum in women with BED, as well as those with AN and BN. Previous studies of these relations have not included women with BED diagnoses, despite increased awareness of its prevalence and clinical significance. ${ }^{48-50}$

Third, we evaluated the association between postpartum depressive symptoms and eating disorders using a measure specifically designed to assess PPD. Most studies investigating the association of these two variables have used structured interviews to assess depression., 2,6 Many established measures of depression may not be the most appropriate assessments of PPD symptomatology, as they emphasize somatic symptoms that may be caused by physiologic changes that are a normal consequence of childbirth. ${ }^{29}$ In the current study, the Edinburgh Postnatal Depression Scale (EPDS) ${ }^{51}$ was used to assess PPD symptoms. The EPDS has been found to be more effective than general depression measures in identifying PPD symptoms. ${ }^{5,53}$ To our knowledge, only one previous 
study $^{34}$ has used the EPDS to evaluate the association between eating disorder diagnoses and PPD. However, Abraham et al. ${ }^{34}$ only assessed PPD in the week after childbirth, a time when many women are still experiencing the relatively normative postpartum blues. Finally, we examined the relevance of specific aspects of perfectionism to PPD, as previous investigations have indicated that particular forms of perfectionism are associated with eating disordered behavior. ${ }^{23-25}$

\section{Method}

\section{Participants}

The twin sample used in the current study comes from two interrelated projects utilizing the population-based Virginia Twin Registry, ${ }^{54}$ which is now the Mid-Atlantic Twin Registry. Study methods were approved by our university's Institutional Review Board. Female-female twin pairs, born between the years of 1934 and 1974, were eligible if both members had previously responded to a mailed questionnaire, the response rate to which was approximately $64 \%$. They have been approached for a total of 4 waves of personal interviews from 1988 to 1997. A complete description of the sample and recruitment has been provided elsewhere. ${ }^{55}$ The current study focuses on the female twins who reported having $\geq 1$ pregnancy $(N=1,119)$. The mean number of pregnancies reported was $2.5(S D=1.3)$.

\section{Measures}

Eating Disorders. Participants completed a selfreport questionnaire designed to assess all criteria for $\mathrm{AN}, \mathrm{BN}$, and BED outlined in the 4 th ed. of the Diagnostic and Statistical Manual of Mental Disorders (DSM-IV; Washington, DC: American Psychiatric Association; 1994). Items were adapted from the Structured Clinical Interview for DSM-IV (SCID1). ${ }^{56}$ Diagnostic algorithms for DSM-IV AN, BN, and BED were constructed from questionnaire items assessing the presence of behavioral and psychological characteristics associated with each diagnostic criterion (Table 1). Because of the relative rarity of DSM-IV AN, we also report frequencies for subthreshold AN ("AN broad"). Complete information on these diagnostic algorithms is available from the authors on request.

Depression during Pregnancy. Depression during pregnancy was assessed by the item, "During how many of your pregnancies did you feel sad or miserablea period of at least two weeks, when you were not yourself and which was worse than the normal ups and downs of life?".
Baby Blues and PPD. The baby blues were assessed by the item, "After how many deliveries did you experience a few days of the 'baby blues,' where you felt very sad, anxious, irritable, tearful, or moody?" PPD was assessed in a two-step fashion. First, participants were asked, "After how many deliveries, within the first six months, did you feel sad or miserable - a period of at least two weeks, when you were not yourself and which was worse than the normal ups and downs of life?" If respondents endorsed this item, they were then asked to complete a modified version of the EPDS. The 10-item EPDS was developed specifically for the purposes of assessing postnatal depression in mothers, as many established assessments of depression emphasize somatic elements of the disorder, which may be caused by physiologic changes that are a normal consequence of childbirth. ${ }^{29}$ In the version of the EPDS used in the current study, women were asked to report about their worst episode of PPD. The original EPDS was designed to be completed by women who are currently postpartum, and thus, asks about the frequency of these symptoms in the last week. Previous research has found that an EPDS cutoff score of 12 correctly identified $86 \%$ of women with PPD. ${ }^{29}$ The developers of the EPDS also found that it yielded internally consistent scores (Cronbach's $\alpha=.87$ ). Subsequent research has found that the EPDS is more accurate at detecting PPD than routine clinical screening. ${ }^{57}$ In the current study, the internal consistency (alpha coefficient) of the EPDS was .83.

Lifetime MDD. In previous waves of the current study, clinically experienced interviewers assessed psychiatric disorders using an adaptation of the Structured Clinical interview for DSM-III-R. ${ }^{56}$ These interviewers received 40 $\mathrm{hr}$ of training and participated in regular review sessions. Complete descriptions of the interview methods have been reported elsewhere. ${ }^{54}$

Perfectionism. Perfectionism was assessed using a subset of items from the Multidimensional Perfectionism Scale (MPS) by Frost et al. ${ }^{58}$ The original MPS includes six subscales: CM, DA, PS, Organization (O), Parental Criticism (PC), and Parental Expectations (PE). Based on previous research with the MPS and communication with the scale's developers, we focused on the subscales that deal with the self-referent aspects of perfectionism (i.e., PS, DA, and CM). In addition, items from the O subscale were not included because this subscale is not believed to capture a core component of perfectionism. ${ }^{58} \mathrm{We}$ selected four items each from the CM and PS subscales that had shown reliable factor loadings in previous investigations. ${ }^{58,59}$ The original DA subscale only includes four items. This version of the MPS has demonstrated factorial validity in a previous study conducted with this sample. $^{44}$ 
TABLE 1. Diagnostic assessment for eating disorders

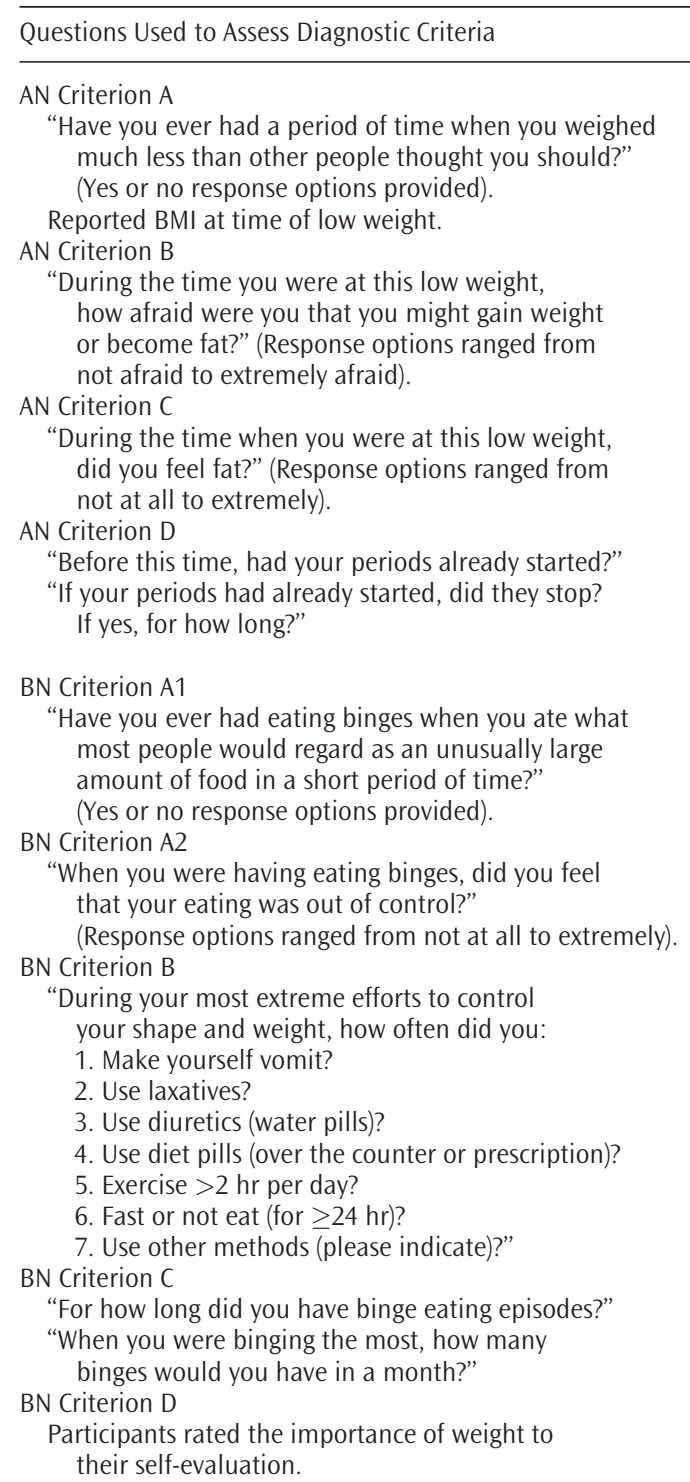

BED Criterion A

Assessed using same items as Criterion A for BN.

BED Criterion B

Binge characteristics were assessed by asking,

"During eating binges, did you:

1. Eat much more rapidly than usual?

2. Eat until you felt uncomfortably full?

3. Eat large amounts of food when you didn't

feel physically hungry?

4. Eat alone because you were embarrassed by how much you were eating?

5. Feel disgusted with yourself, depressed, or very guilty after overeating?"

\section{BED Criterion C}

"How upset or distressed did binge eating usually make you feel?" (Response options ranged from not at all to extremely).
Endorsed low weight item $\mathrm{BMI}$ at that time was $\leq 17.5$

Very afraid or extremely afraid

Very much or extremely

Primary amenorrhea

(no periods and $\geq 16$ years of age)

or secondary amenorrhea with

a duration of $\geq 3$ months

Yes

Somewhat to extremely

"A few days a week" to "every day"

Duration of binge eating $\geq 3$ months

$\geq 8$ binges per month

Endorsed either: "Weight or shape

is the most important thing that

affects how I feel about myself".

or "Weight or shape plays a

major part in how I feel about myself"

Yes to binging and "somewhat"

to "extremely" out of control

during binges

Endorsed $\geq 3$ of these binge

characteristics

Very much or extremely
Not used in current study

Not used in current study

Not used in current study

Not used in current study

Not used in current study

Endorsed low weight item BMI at that time was $<18.5$

Slightly afraid to extremely afraid

Slightly to extremely

Amenorrhea not required

Not used in current study

Not used in current study

Not used in current study 
TABLE 1. Continued

\begin{tabular}{ll}
\hline Questions Used to Assess Diagnostic Criteria & Narrow \\
\hline $\begin{array}{l}\text { BED Criterion D } \\
\text { "For how long did you have binge eating episodes?" }\end{array}$ & $\begin{array}{l}\text { Duration of binge eating } \geq 6 \text { months } \\
\text { "When you were binging the most, how many binges would }\end{array}$ \\
$\begin{array}{l}\text { you have in a month?" } \\
\text { BED Criterion E }\end{array}$ & Do not endorse any compensatory behaviors \\
$\begin{array}{l}\text { "Have you ever done or used the following during a time when } \\
\text { use diuretics (water pills), exercise }>2 \text { hr per day, } \\
\text { fast or not eat (for } \geq 24 \text { hr), other methods-please indicate." }\end{array}$ & \\
\hline
\end{tabular}

Note: $\mathrm{AN}=$ anorexia nervosa; $\mathrm{BMI}=$ body mass index; $\mathrm{BN}=$ bulimia nervosa; $\mathrm{BED}=$ binge eating disorder.

\section{Analysis Plan}

Chi-square analyses were used to determine the percentage of individuals in each eating disorder diagnostic category who reported depression during pregnancy or postpartum. We also examined the correlation between aspects of perfectionism and EPDS scores. Next, we used logistic regression to examine the associations among PPD as assessed by the screening item (which all women completed), eating disorder status, and perfectionism. Lifetime history of major depression was entered in the first step of these logistic regressions so that its influence could be controlled.

Finally, we examined these associations further within the subgroup of women who had endorsed the PPD screening item, and thus, per the survey instructions, completed the EPDS. These regressions were similar to those described previously, except that, because the EPDS is scored on a continuous scale, these were linear, rather than logistic equations. Lifetime major depression was again controlled in all of these regressions.

\section{Results}

\section{Eating Disorder Diagnostic Status, Depression during Pregnancy, and PPD}

Percentages of individuals in each eating disorder diagnostic category who reported symptoms of depression during pregnancy or postpartum are reported in Tables 2 and 3. Only 1 participant met the strict (i.e., narrow) DSM-IV criteria for the AN diagnosis. Thus, information for both AN narrow and AN broad diagnoses are reported. Narrow (i.e., DSM-IV) diagnostic criteria were used for BN and BED in these and all subsequent analyses. Of note, 310 women endorsed the PPD screening item and provided complete EPDS data. Symptoms of depression during pregnancy, baby blues, and PPD were higher in the women with eating disorders (all subtypes) than in women without eating disorders (Tables 2 and 3). In addition, symptoms of depres- sion during pregnancy and postpartum among women with eating disorders were comparable, and in many cases, exceeded, those of women with histories of MDD as can be seen in Tables 2 and 3 .

\section{Correlations between EPDS Scores and Perfectionism Subscales}

Before conducting the regression analyses, we examined correlations among the perfectionism subscales and EPDS scores. Results indicated that EPDS scores were significantly associated with CM and DA ( $r=.34$ and .31 , respectively, $p<.001)$. However, PS was not significantly associated with EPDS scores $(r=.09)$. Thus, these findings suggest that among women who endorsed the PPD screening item (and thus, completed the EPDS), PPD symptoms were moderately associated with these two specific aspects of perfectionism, regardless of eating disorder diagnostic status.

\section{Associations among Eating Disorder Diagnoses, PPD Symptoms, and Perfectionism}

We examined the associations among eating disorders, perfectionism, and PPD symptoms, controlling for lifetime major depression, in two sets of regressions. In the first set of three logistic regressions (one for each eating disorder diagnosis), the PPD screening item, which was completed by the total sample, was used as the dependent variable. MDD diagnostic status was controlled in these analyses. Regressions were conducted separately for each eating disorder diagnostic group. Results indicated that $\mathrm{BN}$ (odds ratio $[\mathrm{OR}]=3.5,95 \%$ confidence interval $[95 \% \mathrm{CI}]=$ 1.3-9.6) and BED (OR = 2.8, 95\% CI = 1.1-7.0) diagnoses were strongly associated with PPD symptoms as assessed by the screening item. However, AN was not $(\mathrm{OR}=1.3,95 \% \mathrm{CI}=0.51-3.3)$. In addition, DA manifested a smaller, but still significant, association with PPD symptoms in all 3 logistic regressions (OR $=1.1$ in all 3 equations). However, the other two MPS subscales were not significantly associated with PPD symptoms. 
TABLE 2. Rates of depression during pregnancy and postpartum across ED subtypes

\begin{tabular}{|c|c|c|c|c|c|c|}
\hline & AN Narrow & AN Broad & BN Narrow & BED Narrow & No ED diagnosis ${ }^{b}$ & \multirow{2}{*}{$\begin{array}{c}\text { MDD and } \\
\text { no ED diagnosis }\end{array}$} \\
\hline PPD Category & $N(\%)$ & $N(\%)$ & $N(\%)$ & $N(\%)$ & $N(\%)$ & \\
\hline Depression during pregnancy & $1 / 1$ & $9 / 23(39.1 \%)$ & $13 / 22(59.1 \%)$ & $18 / 27(66.7 \%)$ & $256 / 950(26.9 \%)$ & $111 / 302(36.8 \%)$ \\
\hline Baby blues & $1 / 1$ & $16 / 23(69.6 \%)$ & $20 / 21(95.2 \%)$ & $25 / 28(89.3 \%)$ & $592 / 959(61.7 \%)$ & $210 / 307(68.6 \%)$ \\
\hline Endorsed PPD Screener & $1 / 1$ & $10 / 22(45.5 \%)$ & $14 / 20(70 \%)$ & $18 / 26(69.2 \%)$ & $286 / 944(30.3 \%)$ & $124 / 301(41.2 \%)$ \\
\hline Exceeded cutoff on EPDS ${ }^{a}$ & $1 / 1$ & $8 / 9(88.9 \%)$ & $13 / 14(92.9 \%)$ & $17 / 18(94.4 \%)$ & $240 / 277(86.6 \%)$ & $111 / 121(91.7 \%)$ \\
\hline
\end{tabular}

Note: $\mathrm{ED}=$ eating disorder; $\mathrm{PPD}=$ postpartum depression; $\mathrm{AN}=$ anorexia nervosa; $\mathrm{BN}=$ bulimia nervosa; $\mathrm{BED}=$ binge eating disorder; $\mathrm{MDD}=$ major depressive disorder; EPDS = Edinburgh Postnatal Depression Scale.

${ }^{\text {a }}$ Only women who endorsed the PPD screening item answered the EPDS. Of this group, 84.7\% exceeded the EPDS cutoff.

${ }^{b}$ No ED diagnosis means no diagnosis of any of the ED assessed in the current study (i.e., AN narrow, AN broad, BN narrow, or BED narrow).

TABLE 3. Rates of depression during pregnancy and postpartum across ED subtypes

\begin{tabular}{|c|c|c|c|c|}
\hline ED Diagnosis & $\begin{array}{l}\text { Depression during Pregnancy } \\
\qquad N(\%)\end{array}$ & $\begin{array}{l}\text { Baby Blues } \\
\qquad N(\%)\end{array}$ & $\begin{array}{l}\text { Endorsed PPD Screener } \\
\qquad N(\%)\end{array}$ & $\begin{array}{c}\text { Exceeded Cutoff on EPDS } \\
\qquad N(\%)^{\mathrm{a}}\end{array}$ \\
\hline AN narrow & $1 / 1$ & $1 / 1$ & $1 / 1$ & $1 / 1$ \\
\hline AN broad & 9/23 (39.1\%) & 16/23 (69.6\%) & $10 / 22(45.5 \%)$ & 8/9 (88.9\%) \\
\hline BN narrow & $13 / 22(59.1 \%)$ & $20 / 21(95.2 \%)$ & $14 / 20(70 \%)$ & $13 / 14(92.9 \%)$ \\
\hline BED narrow & 18/27 (66.7\%) & 25/28 (89.3\%) & $18 / 26(69.2 \%)$ & 17/18 (94.4\%) \\
\hline No ED diagnosis ${ }^{\mathrm{b}}$ & $256 / 950(26.9 \%)$ & $592 / 959(61.7 \%)$ & $286 / 944(30.3 \%)$ & $240 / 277(86.6 \%)$ \\
\hline MDD and no ED diagnosis ${ }^{b}$ & $111 / 302(36.8 \%)$ & $210 / 307$ (68.6\%) & $124 / 301(41.2 \%)$ & $111 / 121(91.7 \%)$ \\
\hline
\end{tabular}

Note: $\mathrm{ED}=$ eating disorder; PPD = postpartum depression; EPDS = Edinburgh Postnatal Depression Scale; AN = anorexia nervosa; BN = bulimia nervosa; $\mathrm{BED}=$ binge eating disorder; $\mathrm{MDD}=$ major depressive disorder.

${ }^{a}$ Only women who endorsed the PPD screening item answered the EPDS. Of this group, 84.7\% exceeded the EPDS cutoff.

${ }^{b}$ No ED diagnosis means no diagnosis of any of the EDs disorders assessed in the current (i.e., AN narrow, AN broad, BN narrow, or BED narrow).

Next, we examined the influence of perfectionism on the association between eating disorder diagnostic status and PPD symptoms, as measured by the EPDS. These analyses provided important additional information, as they were conducted on a subset of the sample (i.e., those who reported PPD symptoms on the screening item). Because the EPDS yields continuous scores, multiple linear regression analyses were performed that included the three MPS subscales and eating disorder diagnostic status as independent variables. The influence of lifetime MDD was statistically controlled for in these analyses. Results indicated that, in all three regressions (one for each of the eating disorder diagnoses assessed), PS was negatively associated with EPDS scores, and CM was positively associated with the EPDS. The DA subsclale was not associated with EPDS scores in any of these regressions (Table 4). Similarly, AN, BN, and BED were not associated with EPDS scores. These findings suggest that, among individuals who reported symptoms of PPD (i.e., on the screening item), the severity of these symptoms may be accounted for by specific aspects of perfectionism, primarily $\mathrm{CM}$.

\section{Conclusion}

The current study suggests that levels of depressive symptoms during pregnancy and postpartum are high among women with histories of eating disorders. Indeed, women with eating disorders appear to be at as much, if not greater, risk for developing depression during pregnancy or postpartum as are women with a history of MDD. In particular, individuals with a history of BN or BED have approximately three times the risk of developing PPD symptomatology than do women without these eating disorders. These high levels of depressive symptoms among women with eating disorders during pregnancy and postpartum could be due to body dissatisfaction associated with pregnancyrelated weight and shape changes.

However, among the subsample of women who endorsed symptoms of PPD, regression analyses suggest that $\mathrm{CM}$ is associated with the severity of this symptomatology. CM is an aspect of perfectionism common among women with eating disorders. ${ }^{23-25}$ These findings extend previous literature that has highlighted the relevance of specific aspects of perfectionism to eating disorders. For example, Bulik et al. $^{25}$ found that elevated CM was specifically associated with eating disorders. In contrast, PS was not associated with any of the seven psychiatric disorders studied. The observed positive association between $\mathrm{CM}$ and PPD is also noteworthy in light of Tozzi et al.'s ${ }^{44}$ finding that, compared with PS and DA, CM is a more central feature of perfectionism. The results of their multivariate structural analyses indicated 
TABLE 4. Results of regression analyses with EPDS scores as the criterion

\begin{tabular}{|c|c|c|c|c|c|c|}
\hline & Predictors & Beta & SEB & $p$ & $R^{2}$ & $F$ \\
\hline \multicolumn{7}{|c|}{ I. AN and perfectionism } \\
\hline Step 1 & MDD & $.29 * *$ & .56 & .000 & .09 & $26.47^{* *}$ \\
\hline \multirow[t]{4}{*}{ Step 2} & AN & .08 & 1.59 & .148 & .21 & $14.95^{* *}$ \\
\hline & Personal standards & $-.17^{*}$ & .09 & .013 & & \\
\hline & Concern over mistakes & $.32^{* *}$ & .10 & .000 & & \\
\hline & Doubts about actions & .12 & .10 & .113 & & \\
\hline \multicolumn{7}{|c|}{ I. BN and perfectionism } \\
\hline Step 1 & MDD & $.29^{* *}$ & .56 & .000 & .08 & $25.74 * *$ \\
\hline \multirow[t]{4}{*}{ Step 2} & $\mathrm{BN}$ & .06 & 1.3 & .276 & .21 & $14.47^{* *}$ \\
\hline & Personal standards & $-.17^{*}$ & .09 & .013 & & \\
\hline & Concern over mistakes & $.30^{* *}$ & .10 & .001 & & \\
\hline & Doubts about actions & .13 & .10 & .087 & & \\
\hline \multicolumn{7}{|c|}{ II. BED and perfectionism } \\
\hline Step 1 & MDD & $.29^{* *}$ & .56 & .000 & .09 & $26.47^{* *}$ \\
\hline \multirow[t]{4}{*}{ Step 2} & BED & .04 & 1.22 & .508 & .21 & $14.53 * *$ \\
\hline & Personal standards & $-.17^{*}$ & .09 & .013 & & \\
\hline & Concern over mistakes & $.32^{* *}$ & .10 & .000 & & \\
\hline & Doubts about actions & .11 & .10 & .122 & & \\
\hline
\end{tabular}

Note: EPDS = Edinburgh Postnatal Depression Scale; $\mathrm{AN}=$ anorexia nervosa; $\mathrm{BN}=$ bulimia nervosa; MDD = major depressive disorder; BED = binge eating disorder.

${ }^{* *} p<.01 .{ }^{*} p<.05$.

that CM reflected the "core" feature of perfectionism (p 490).

The current findings also bring attention to the need for prenatal care providers to assess patients' histories of eating disorders. Research has found that most pregnant women with active eating disorders do not report their eating problems to their obstetrician. ${ }^{10}$ Thus, it is also unlikely that women with past eating disorders report their history of eating problems to their obstetrician or midwife. Yet, our findings suggest that women with a history of eating disorders may be at particular risk for depression during pregnancy and postpartum. This risk may be attributable to the fact that perfectionism is more of an enduring trait that tends to persist in individuals who have recovered from eating disorders. ${ }^{38-41}$

The finding that PS was negatively associated with PPD severity in the linear regressions was somewhat unexpected. However, as has been noted by the developers of the MPS, ${ }^{58}$ this subscale is associated with more functional and socially advantageous achievement striving. Tozzi et al. ${ }^{44}$ also found that the PS subscale was normally distributed, whereas the CM and DA subscales were not, further suggesting that PS reflects more functional behavior. In sum, the current results provide additional support for the importance of considering the different structural components of perfectionism, and using measures of specific aspects of this trait.

The results of the current study should be considered in the light of potentially important limitations. First, due to the format of the data collection, it is not clear when participants had their child or children (or associated depression), or when they experienced their reported eating symptoms. However, these results do highlight potential sources of vulnerability. Specifically, women with eating disorders or a history of them appear to be particularly vulnerable to PPD, and this association appears to be attributable, at least in part, to a link between perfectionism and eating pathology. Given the significant body of research documenting the persistence of perfectionism among individuals who have recovered from $\mathrm{AN}$ and $\mathrm{BN},{ }^{38-41}$ the current findings argue for more thorough assessment of an eating disorder history and associated traits among pregnant women. In addition, assessing the features of perfectionism in pregnant women might help to identify at-risk individuals, and facilitate primary prevention of PPD.

Another limitation of this study is that the high levels of PPD symptoms found among women with eating disorders in this sample could be attributable to the comorbidity of MDD and eating disorders. ${ }^{12-19}$ However, we controlled for previous lifetime major depression in the regression analyses, something that has not been done in previous investigations of the association between PPD and eating disorders. Our data are also limited due to the format of the survey. Specifically, only women who endorsed the PPD screening item were instructed to complete the EPDS. Thus, we lack information on the full range of PPD scores and their correlates. However, we did use all women's scores on the PPD screening item in the logistic regression analyses, thereby partially addressing 
this concern. Finally, although we have found previously ${ }^{55}$ that the demographics of our sample are comparable to those obtained in other twin studies (i.e., higher participation by individuals with more education), ${ }^{60}$ other biases might exist. Finally, some people may have been misclassified as experiencing PPD symptoms or an eating disorder, based on their self-report. Future studies should examine the association between PPD and eating disorders using multiple measurement strategies.

Despite these limitations, the current study has several strengths, including the use of a relatively large, non-treatment-seeking, population-based sample, the inclusion of participants with BED as well as those with $\mathrm{AN}$ and $\mathrm{BN}$, the use of a wellvalidated measure of PPD, and the ability to control statistically for the influence of lifetime MDD. Moreover, the findings have significant clinical relevance for healthcare providers working with pregnant women with current and past eating disorders. Specifically, providers should be alert to signs of depression and screen patients for both depression and eating disorders. Previous studies have found that the EPDS is an efficient and effective screening tool for PPD in a clinical setting, and, in fact, is superior to routine clinical assessment. ${ }^{57}$ There are also several brief, self-report questionnaires to assess eating disorder symptomatology, with which the readers of this journal are familiar (e.g., Eating Disorders Examination-Questionnaire version) ${ }^{61}$ In addition, the Eating Disorder Screen for Primary Care (ESP) is a four-item measure that has demonstrated validity in clinical settings. ${ }^{62}$ Given the significant impact that PPD can have on the health of both mothers and their offspring, as well as the effectiveness of treatment, ${ }^{28,30}$ early detection and treatment appear invaluable.

\section{References}

1. Carter FA, Mclntosh VVW, Frampton CM, et al. Predictors of childbirth following treatment for bulimia nervosa. Int J Eat Disord 2003;34:337.

2. Franko DL, Blais MA, Becker AE, et al. Pregnancy complications and neonatal outcomes in women with eating disorders. Am J Psychiatry 2001;158:1461.

3. Little L, Lowkes E. Critical issues in the care of pregnant women with eating disorders and the impact on their children. J Midwifery Womens Health 2000;45:301.

4. Morgan JF, Lacey JH, Sedgwick PM. Impact of pregnancy on bulimia nervosa. Br J Psychiatry 1999;174:135.

5. Blais MA, Becker AE, Burwell RA, et al. Pregnancy: outcome and impact on symptomatology in a cohort of eating-disordered women. Int J Eat Disord 2000;27:140.

6. Carter FA, Mclntosh VVW, Joyce PR, et al. Bulimia nervosa, childbirth, and psychopathology. J Psychosom Res 2003;55:357.
7. Lacey JH, Smith G. Bulimia nervosa: the impact of pregnancy on mother and baby. Br J Psychiatry 1987;150:777.

8. Mitchell-Gieleghem A, Mittelstaedt ME, et al. Eating disorders and childbearing: concealment and consequences. Birth 2002; 29:182.

9. Lemberg R, Phillips J, Fischer JE. The obstetric experience of primigravida anorexic and bulimic women-some preliminary observations. Br Rev Bulimia Anorexia Nervosa 1992;6:31.

10. Lemburg R, Phillips J. The impact of pregnancy on anorexia and bulimia nervosa. Int J Eat Disord 1989;8:285.

11. Stein A, Fairburn CG. Eating habits and attitudes to body shape and weight in the postpartum period. Psychosom Med 1996; 58:321.

12. Braun DL, Sunday SR, Halmi KA. Psychiatric comorbidity in patients with eating disorders. Psychol Med 1994;24:859.

13. Brewerton TD, Lydiard RB, Herzog DB, et al. Comorbidity of axis I psychiatric disorders in bulimia nervosa. J Clin Psychiatry 1995;56:77.

14. Bushnell JA, Wells E, McKenzie JM, et al. Bulimia comorbidity in the general population and in the clinic. Psychol Med 1994;24:605.

15. Hudson JI, Pope HG, Jonas J, et al. Phenomenologic relationship of eating disorders to major affective disorder. Psychiatry Res 1983;9:345.

16. Hudson JI, Pope HG, Yurgelun-Todd D, et al. A controlled study of lifetime prevalence of affective and other psychiatric disorders in bulimic outpatients. Am J Psychiatry 1987;144:1283.

17. Kendler KS, MacLean C, Neale M, et al. The genetic epidemiology of bulimia nervosa. Am J Psychiatry 1991;148:1627.

18. Laessle R., Kittl S., Fichter M., et al. Major affective disorder in anorexia nervosa and bulimia. Br J Psychiatry 1987;151:785.

19. Mitchell J, Specker S, DeZwaan M. Comorbidity and medical complications of bulimia nervosa. J Clin Psychiatry 1991;52: 13.

20. Woodside DB, Shekter-Wolfson LF. Parenting by patients with anorexia nervosa and bulimia nervosa. Int J Eat Disord 1990;9:303.

21. Franzen U, Gerlinghoff M. Parenting by patients with eating disorders: experiences with a mother-child group. Eat Disord 1997;5:5.

22. Welch SL, Doll HA, Fairburn CG. Life events and the onset of bulimia nervosa: a controlled study. Psychol Med 1997;27: 515.

23. Halmi KA, Sunday SR, Strober M, et al. Perfectionism in anorexia nervosa: variation by clinical subtype, obsessionality, and pathological eating behavior. Am J Psychiatry 2000;157:1799.

24. Lilenfeld LR, Stein D, Bulik CM, et al. Personality traits among currently eating disordered, recovered and never ill first-degree female relatives of bulimic and control women. Psychol Med 2000;30:1399.

25. Bulik CM, Tozzi F, Anderson C, et al. A unique relation between components of perfectionism and eating disorders. Am J Psychiatry 2003;160:366.

26. Josefsson A, Berg G, Nordin C, et al. Prevalence of depressive symptoms in late pregnancy and postpartum. Acta Obstet Gynecol Scand 2001;80:251.

27. Kitmura T, Sugawara M, Sugawara K, et al. Psychosocial study of depression in early pregnancy. Br J Psychiatry 1996;168:732.

28. Moses-Kolko EL, Roth EK. Antepartum and postpartum depression: healthy mom, healthy baby. J Am Med Womens Assoc 2004;59:181.

29. Cox JL, Holden JM, Sagovsky R. Detection of postnatal depression: development of the 10-item Edinburgh Postnatal Depression Scale. Br J Psychiatry 1987;150:782.

30. Mitchell LJ. Postpartum depression. JAMA 2002;287:762.

31. Setfried LS, Marcus SM. Postpartum mood disorders. Int Rev Psychiatry 2003;15:231. 
32. Kassett J, Gershon E, Maxwell M, et al. Psychiatric disorders in the first-degree relatives of probands with bulimia nervosa. Am J Psychiatry 1989;146:1468.

33. Abraham S. Sexuality and reproduction in bulimia nervosa patients over 10 years. J Psychosom Res 1998;44:491.

34. Abraham S, Taylor A, Conti J. Postnatal depression, eating, exercise, and vomiting before and during pregnancy. Int J Eat Disord 2001;29:482.

35. Anderluh MB, Tchanturia K, Rabe-Hesketh S, et al. Childhood obsessive-compulsive personality traits in adult women with eating disorders: defining a broader eating disorder phenotype. Am J Psychiatry 2003;160:242.

36. Fairburn CG, Cooper Z, Doll HA, et al. Risk factors for anorexia nervosa: three integrated case-control comparisons. Arch Gen Psychiatry 1999;56:468.

37. Fairburn CG, Welch SL, Doll HA, et al. Risk factors for bulimia nervosa: a community-based case-control study. Arch Gen Psychiatry 1997;54:509.

38. Bastiani AM, Rao R, Weltzin T, et al. Perfectionism in anorexia nervosa. Int J Eat Disord 1995;17:147.

39. Srinivasagam NM, Kaye WH, Plotnicov KH, et al. Persistent perfectionism, symmetry, and exactness after long-term recovery from anorexia nervosa. Am J Psychiatry 1995;152:1630.

40. Kaye WH, Greeno CG, Moss H, et al. Alterations in serotonin activity and psychiatric symptoms after recovery from bulimia nervosa. Arch Gen Psychiatry 1998;55:927.

41. Sutandar-Pinnock K, Woodside DB, Carter JC, et al. Perfectionism in anorexia nervosa: a 6-24-month follow-up study. Int J Eat Disord 2003;33:225.

42. Lilenfeld LR, Kaye WH, Greeno CG, et al. A controlled family study of anorexia nervosa and bulimia nervosa: psychiatric disorders in first-degree relatives and effects of proband comorbidity. Arch Gen Psychiatry 1998;55:603.

43. Woodside DB, Bulik CM, Halmi KA, et al. Personality, perfectionism, and attitudes toward eating in parents of individuals with eating disorders. Int J Eat Disord 2002;31:290.

44. Tozzi F, Aggen SH, Neale B, et al. The structure of perfectionism: a twin study. Behav Genet 2004;34:483.

45. Dunkley DM, Blankstein KR, Halsall J, et al. The relation between perfectionism and distress: hassles, coping, and perceived social support as mediators and moderators. J Couns Psychol 2000;47:437.

46. Fairburn CG, Welch SL, Norman PA, et al. Bias and bulimia nervosa: how typical are clinic cases? Am J Psychiatry 1996;153: 386.
47. Bushnell JA, Wells E, McKenzie JM, et al. Bulimia comorbidity in the general population and in the clinic. Psychol Med 1994; 24:605.

48. Bulik CM, Sullivan PF, Kendler KS. Medical and psychiatric morbidity in obese women with and without binge eating. Int J Eat Disord 2002;32:72.

49. Striegel-Moore RH, Franko DL. Epidemiology of binge eating disorder. Int J Eat Disord 2003;34:S19.

50. Wilfley DE, Wilson GT, Agras WS. The clinical significance of binge eating disorder. Int J Eat Disord 2003;34:596

51. Cox JL, Holden JM, Sagovsky R. Detection of postnatal depression. Development of the 10-item Edinburgh Postnatal Depression Scale. Br J Psychiatry 1987;150:782

52. Grazioli R, Terry DJ. The role of cognitive vulnerability and stress in the prediction of postpartum depressive symptomatology. Br J Clin Psychol 2000;39:329.

53. Lee DT, Yip AS, Chiu HF, et al. Screening for postnatal depression using the double-test strategy. Psychosom Med 2000;62: 258.

54. Kendler K, Prescott C. A population-based twin study of lifetime major depression in men and women. Arch Gen Psychiatry 1999; 56:39.

55. Mazzeo SE, Aggen SH, Anderson C, et al. Investigating the structure of the Eating Inventory (Three-Factor Eating Questionnaire): a confirmatory approach. Int J Eat Disord 2003;34: 255.

56. First MB, Spitzer RL, Gibbon M, et al. Structured Clinical Interview for DSM-IV Axis I Disorders (SCID-I), Clinician Version. Washington, DC: American Psychiatric Press; 1997.

57. Evins GG, Theofrastous JP, Galvin SL. Postpartum depression: a comparison of screening and routine clinical evaluation. Am J Obstet Gynecol 2000;182:1080.

58. Frost R, Marten P, Lahart C, et al. The dimensions of perfectionism. Cogn Ther Res 1990;14:449.

59. Rheaume J, Freeston M, Dugas M, et al. Perfectionism, responsibility and obsessive-compulsive symptoms. Behav Res Ther 1995;33:785.

60. Lykken DT, McGue M, Tellegen A. Recruitment bias in twin research: the rule of two-thirds reconsidered. Behav Genet 1987; $17: 343$

61. Fairburn CG, Beglin SJ. Assessment of eating disorders: interview or self-report questionnaire. Int J Eat Disord 1994;16:363.

62. Cotton MA, Ball C, Robinson P. Four simple questions can help screen for eating disorders. J Gen Intern Med 2003;18:53. 